\title{
Dietary Strategies to Reduce the Bioaccessibility of Arsenic from Food
}

\section{Matrices}

María Jesús Clemente, Vicenta Devesa, and Dinoraz Vélez *

Instituto de Agroquímica y Tecnología de Alimentos (IATA-CSIC), Av. Agustín Escardino 7, 46980 Paterna (Valencia), Spain.

* To whom correspondence should be addressed (telephone (+34) 963900 022; fax (+34) 963 636 301; e-mail: deni@iata.csic.es)

\section{ABSTRACT}

The main route of exposure to arsenic (As) is the consumption of water and foods, in which the forms with greatest toxicity are inorganic As and dimethylarsinic acid, DMA(V). The objective of this study was to search for dietary components that reduce the bioaccessibility of As from food and water, in order to reduce the amount of As available for absorption. For this purpose, 35 compounds were assayed using a static in vitro model of gastrointestinal digestion. Sulfates of Fe(II) and Fe(III) reduced the solubility of inorganic As (86-99\%) and DMA(V) in aqueous solution (40-66\%). This reduction was also observed in rice (100\%) and seaweed (60\%). Aluminum, titanium, and tannic acid also reduced the bioaccessibility of As from food (42-70\%). These data show that the use of dietary components may be a good strategy to reduce the entry of As into the systemic circulation.

Keywords: arsenic, bioaccessibility, dietary strategies, food, rice, seaweed. 


\section{INTRODUCTION}

Arsenic (As) is present in the environment in variable concentrations affected by the proximity of sources of natural or anthropogenic pollution. For most of the population the main path by which this element enters the organism is oral, through consumption of food and drinking water.

The World Health Organization recommends a maximum concentration of $10 \mu \mathrm{g} / \mathrm{L}$ in water intended for human consumption. ${ }^{1}$ However, in many parts of the world the population is exposed to much higher As concentrations in water. ${ }^{2}$ The consumption of this water and the use of it for preparing food is reflected in high levels of As in urine, a biomarker of exposure to this contaminant. A typical background urinary concentration of inorganic As and its metabolites for non-exposed individuals is considered to be $8 \pm 6 \mu \mathrm{g}$ As/g creatinine (roughly equal to $10 \pm 8 \mu \mathrm{g} / \mathrm{L}){ }^{3}$ However, values close to $1000 \mu \mathrm{g}$ As/L can be found in areas affected by naturally occurring arsenic-contaminated water. ${ }^{4}$ This chronic exposure to As leads to an increase in the incidence of various types of pathologies. Inorganic As [As(III) + As(V)], the most toxic chemical form of As that has been found in food to date, is associated with a greater prevalence of some types of cancer, type 2 diabetes, cardiovascular diseases, and skin disorders. $^{5-6}$

In areas where water is not naturally contaminated, food is the main source of exposure to this contaminant. In a recent report on As, the European Food Safety Agency (EFSA) identified rice, seafood, algae, wheat bread and rolls, and bottled water as the food matrices that contributed most to the intake of inorganic As by the European population. ${ }^{6}$ EFSA indicated that, although high consumers of rice and algae-based products had a daily dietary exposure within the range of the reference values, the possibility of risk could not be excluded. ${ }^{6}$ Therefore they recommended reducing dietary exposure to inorganic As. 
One way of achieving this objective is by marketing products with lower concentrations of inorganic As. Rice is the food that has been studied most in this context, and possible mitigation measures based on acting on environmental and agricultural factors have been proposed. ${ }^{7}$ It has been shown that As uptake in rice is driven by transporters of silicon and aquaporins that are present in the roots, and that it is translocated by the transporter AtACR2 from the roots to the edible parts. ${ }^{8}$ Strategies aimed at reducing this transport have been designed on the basis of this information. It has been seen that fertilization with silicon reduces As concentrations and produces changes in speciation, with a decrease in inorganic As concentrations and an increase in the dimethylated forms. ${ }^{9-10}$ It has also been shown that AtACR2 transgenic rice plants accumulated 3- to 4-fold less As in rice straw and seed grains. ${ }^{11}$ These strategies involve a change in the type of crop that is grown or the creation of genetically modified foods, which makes implementation difficult.

Another way of reducing exposure to As could be by reducing its entry into systemic circulation. After ingestion of food and water, gastrointestinal digestion and subsequent absorption of As by the intestinal epithelium affect the quantity of the toxic trace element that is bioavailable. It has been shown that the bioavailability of As is less from some vegetables than from other foods, and these results have been associated with the composition of the food matrix. ${ }^{12}$ The fact that components of the diet can alter intestinal absorption of forms of As might provide a line of action to reduce the entry of As into systemic circulation.

The aim of this study was to seek dietary strategies that could reduce the bioaccessibility of As from food (quantity of As that is released from its matrix during gastrointestinal digestion), in order to decrease the amount available for intestinal absorption. An in vitro approach was used to evaluate the effect of 35 dietary components on the quantity of solubilized As solubilizado after gastrointestinal digestion. 


\section{MATERIALS AND METHODS}

Arsenic Standard Solutions. The standard of $\mathrm{As}(\mathrm{V})\left(1000 \mathrm{mg} / \mathrm{L}, \mathrm{As}_{2} \mathrm{O}_{5}\right)$ was obtained from Merck (VWR, Spain). The standard of As(III) (1000 mg/L) was prepared by dissolving 1.320 g of $\mathrm{As}_{2} \mathrm{O}_{3}$ (Riedel de Haën, Spain) in $25 \mathrm{~mL}$ of 20\% (m/v) KOH (Panreac, Spain), neutralizing with 20\% (v/v) $\mathrm{H}_{2} \mathrm{SO}_{4}$ (Merck, Spain), and diluting to 1 liter with $1 \%(\mathrm{v} / \mathrm{v}$ ) $\mathrm{H}_{2} \mathrm{SO}_{4}$. The standard solution of dimethylarsinic acid, DMA(V), was prepared by dissolving the appropriate quantity of $\left(\mathrm{CH}_{3}\right)_{2} \mathrm{AsNaO}_{2} \cdot 3 \mathrm{H}_{2} \mathrm{O}$ (Fluka, Spain) in water.

Food Samples. Various batches of Hizikia fusiforme seaweed (hijiki; n=11) purchased in the city of Valencia (Spain) and various types of white rice $(n=10)$ and brown rice $(n=11)$ provided by Spanish producers of this cereal were used. The seaweed was boiled in deionized water for $20 \mathrm{~min}$ (sample/water ratio: 1/4, w/w), and the water that remained after the process was discarded. The rice samples were boiled in a standard solution of $1 \mathrm{mg} / \mathrm{L}$ of $\mathrm{As}(\mathrm{V})$ until all the water had been adsorbed (sample/water ratio: 1/4). A sample of a given batch/type of seaweed or rice was used for several cooking processes and the product resulting from each of them (21 samples of seaweed, 22 samples of white rice, and 22 samples of brown rice) was considered as a basic sample for the study. The in vitro gastrointestinal digestion was applied to the cooked samples within $24 \mathrm{~h}$ of their preparation.

Influence of Dietary Components on the Solubility or Bioaccessibility of As. An in vitro method that emulates the gastric and intestinal phases of human gastrointestinal digestion ${ }^{13}$ was applied to standard solutions of As species [1 mg/L of As(III), As(V), and DMA, assayed individually] and cooked food (10 g of rice or seaweed). The process was performed with and without the presence of the food components ( $n=35$, Table 1$)$ to determine their effect on As solubility. The concentrations of these compounds were selected on the basis of their usual 
concentrations in food or the quantities used by the food industry. Only the compounds that were effective in reducing the solubility of As in aqueous standards were assayed in food.

To simulate the gastric step, samples were weighed in an Erlenmeyer flask, $80 \mathrm{~g}$ of deionized water was added, and the mixture was homogenized by mechanical shaking. The $\mathrm{pH}$ was adjusted to 2 with $6 \mathrm{~mol} / \mathrm{L} \mathrm{HCl}$. A solution of pepsin $(0.1 \mathrm{~g}$ of pepsin/mL prepared in $0.1 \mathrm{~mol} / \mathrm{L} \mathrm{HCl}$ ) was added in order to obtain $0.02 \mathrm{~g}$ of pepsin/100 $\mathrm{g}$ of solution to be digested. The mixture was made up to a weight of $100 \mathrm{~g}$ with deionized water and incubated at $37^{\circ} \mathrm{C}$ for $2 \mathrm{~h}$ with constant shaking (120 rpm/min). The digest was then subjected to the intestinal step by increasing the $\mathrm{pH}$ to 6.5 by means of $1 \mathrm{~mol} / \mathrm{L} \mathrm{NH}_{4} \mathrm{HCO}_{3}$ and adding a solution of pancreatin and bile extract $(0.004 \mathrm{~g} / \mathrm{mL}$ of pancreatin and $0.025 \mathrm{~g} / \mathrm{mL}$ of bile extract in 0.1 $\mathrm{mol} / \mathrm{L} \mathrm{NH}_{4} \mathrm{HCO}_{3}$ ) to obtain a final concentration of $0.0025 \mathrm{~g}$ of pancreatin/100 $\mathrm{g}$ of solution to be digested and $0.015 \mathrm{~g}$ of bile extract $/ 100 \mathrm{~g}$ of solution to be digested. The mixture was incubated at $37{ }^{\circ} \mathrm{C}$ for $2 \mathrm{~h}$ with constant shaking (120 rpm/min). When the intestinal phase had finished, the $\mathrm{pH}$ was adjusted to 7.2 with $\mathrm{NH}_{4}$.

The digest obtained after applying the in vitro gastrointestinal digestion model was centrifuged $\left(10000 \mathrm{rpm} / 30\right.$ minutes $/ 4{ }^{\circ} \mathrm{C}$ ) to separate the soluble (bioaccessible) fraction from the residue. The As concentration was quantified in the soluble fraction, and the bioaccessibility was determined by means of the following equation:

$$
\text { Bioaccessibility }=[\mathrm{S} / \mathrm{C}] \times 100
$$

where: $\quad \mathrm{S}$ is the total As concentration in the soluble fraction obtained after gastrointestinal digestion.

$\mathrm{C}$ is the total As concentration in the sample or in the standard solutions of As species. 
Determination of Total As. The analysis of the total As contents of the foods and of the bioaccessible fractions was performed by flow injection-hydride generation-atomic absorption spectrometry (FI-HG-AAS; Perkin Elmer, Spain) after a dry ashing step. ${ }^{14}$ A rice flour reference material (SRM1568a), obtained from the National Institute of Standards and Technology (NIST), with a certified As concentration of $0.29 \pm 0.03 \mathrm{mg} / \mathrm{kg}$ was used for quality control of the method.

Determination of $\mathrm{Ca}, \mathrm{Mg}, \mathrm{K}, \mathrm{Fe}$, and $\mathbf{P}$ in the Bioaccessible Fraction. The soluble fractions from the gastrointestinal digestion were digested using a microwave accelerated reaction system (MARS, CEM, Vertex, Spain). The samples (4 mL) were placed in Teflon reactors, and $4 \mathrm{~mL}$ of $14 \mathrm{~mol} / \mathrm{L} \mathrm{HNO}_{3}$ (Merck) and $1 \mathrm{~mL}$ of $\mathrm{H}_{2} \mathrm{O}_{2}$ (30\% v/v, Prolabo, Spain) were added. The reactors were irradiated $\left(180^{\circ} \mathrm{C}, 15 \mathrm{~min}\right)$, and the digest obtained made up to volume with deionized water. The elements were quantified by inductively coupled plasma optical emission spectrometry (4300 DV model, Perkin Elmer) with the following operating conditions: plasma Ar flow, $15 \mathrm{~mL} / \mathrm{min}$; auxiliary Ar flow, $0.2 \mathrm{~mL} / \mathrm{min}$; nebulizer Ar flow, $0.8 \mathrm{~mL} / \mathrm{min}$; RF power, $1300 \mathrm{~W}$; sample uptake, $2 \mathrm{~mL} / \mathrm{min}$; number of replicates, 3; wavelengths (nm): Ca 317.933, Mg 285.213, K 766.490, Fe 238.204, P 213.617). The standards of Ca, Mg, K, Fe, and P were purchased from Merck.

Statistical Analysis. A statistical analysis was performed using one-way ANOVA with multiple comparisons with Tukey HSD test (Sigma Plot version 12.5). Differences were considered significant for $\mathrm{p}<0.05$. 


\section{RESULTS}

\section{Effect of Dietary Components on Solubility of As(V), As(III), and DMA(V) Standard}

Solutions. The 35 compounds assayed (Table 1) showed differing effects on the solubility of As species. As(III) was the species for which the compounds were most effective, as only chitosan and methylcellulose (MC) did not significantly reduce its solubility. For As(V), no reduction in solubility was achieved with phytates, copper sulfate, citric acid, sodium alginate, carboxymethylcellulose (CMC), and $\lambda$ carrageenan. DMA(V) was the least affected chemical form; its solubility was only reduced by $43 \%$ of the compounds assayed.

The compounds that reduced the solubility by more than 30\% are shown in Figures 1 to 3. The largest reductions of As(III) (Figure 1) took place in the presence of iron (86-99\%), titanium dioxide (42-67\%), the Ca/phytates combination (53-60\%), N-acetylcysteine NAC (45-50\%), hydroxypropyl cellulose HPC (40-45\%), oxalic acid (37-40\%), and saponin (3442\%). The solubility of As(V) (Figure 2) was reduced better with salts [Fe(III): >96\%, Fe(II): $>90 \%, \mathrm{Al}(\mathrm{III}):>93 \%, \mathrm{Ti}(\mathrm{II}): 42-79 \%$ ] than with compounds of greater structural complexity such as Ca/phytate (47-51\%) or HPC (33-43\%). With regard to DMA(V) (Figure 3), the most effective compounds were the iron salts (40-66\%), the Ca/phytate combination (27-48\%), and HPC (24-33\%).

Effect of Dietary Components on Bioaccessibility of As from Food. The total As concentrations in rice samples reported in the literature rarely exceed $1 \mathrm{mg} / \mathrm{kg} .{ }^{6,15}$ To evaluate the effect of the dietary components on the bioaccessibility of As more precisely it was considered necessary to work with rice cooked with water containing As(V). This process increases the As concentration in the sample considerably and emulates the situation of populations that live in areas contaminated by this element. In this study, white rice cooked with contaminated water had a total As concentration of $0.98-1.40 \mathrm{mg} / \mathrm{kg}$ fresh weight, fw 
(median $1.03 \mathrm{mg} / \mathrm{kg} \mathrm{fw}$ ), similar to that found in brown rice (1.16-1.79 $\mathrm{mg} / \mathrm{kg} \mathrm{fw}$; median $1.23 \mathrm{mg} / \mathrm{kg} \mathrm{fw}$ ). The bioaccessibility from cooked white rice (73-106\%, median 95\%) was significantly greater than from brown rice (63-95\%, median 75\%). The As concentrations in the bioaccessible fraction were high for both types of grain (white rice: $0.72-1.40 \mathrm{mg} / \mathrm{kg} \mathrm{fw}$; brown rice: $0.81-1.76 \mathrm{mg} / \mathrm{kg} \mathrm{fw})$.

With regard to the seaweed Hizikia fusiforme, the As concentrations ranged between 6.52 and $10.8 \mathrm{mg} / \mathrm{kg}$ fw (median $9.31 \mathrm{mg} / \mathrm{kg} \mathrm{fw}$ ). The As bioaccessibility (45-103\%, median 74\%) and the As concentrations in the bioaccessible fraction of the samples analyzed were also high (5.23-9.43 mg/kg fw), so it was not considered necessary to boil them in water containing As, as was done with the rice samples.

The effects of the food components on the bioaccessibility of As from cooked samples of white rice, brown rice, and seaweed are shown in Figures 4 to 6. The results obtained reveal behavior similar to that observed in the standards of As species, given that most of the components selected produced reductions in bioaccessibility of As. Of the inorganic compounds employed, only manganese oxide did not bring about significant changes in the bioaccessibility of As from rice; however, it reduced the bioaccessibility of As from seaweed at the two concentrations assayed (24 \pm 2 and $39 \pm 1 \%$ ). The decrease in the bioaccessibility of As produced by the two forms of iron was particularly noteworthy. The higher concentration (100 g) almost completely reduced the bioaccessibility of the As present in the rice samples and had a considerable effect on the seaweed, with reductions of (53 \pm 1$) \%$ and (58 \pm 1$) \%$. Aluminum sulfate and titanium dioxide were also effective components for reducing As bioaccessibility. Digestion in the presence of the higher concentration of aluminum (50 mg) brought about substantial reductions in the three food matrices (white rice $68 \pm 2 \%$; brown rice $58 \pm 3 \%$; seaweed $46 \pm 1 \%$ ). The higher concentration of titanium 
dioxide (20 mg) reduced the bioaccessibility in rice and seaweed equally (45 \pm 2 and $54 \pm 1 \%$ respectively).

As for the compounds with a more complex structure, their effectiveness in the reduction of solubilized As during digestion was less, especially for rice. In white and brown rice, the greatest reduction was achieved with tannic acid (42 $\pm 1 \%$ and $45 \pm 2 \%$, respectively). With respect to seaweed, sodium alginate (52 $\pm 4 \%$ ), Ca/phytate (49 $\pm 1 \%$ ), xylan (44 $\pm 2 \%$ ), malic acid (42 \pm 5\%), lignin (41 $\pm 1 \%$ ) and tannic acid (35 $\pm 6 \%$ ), were the most effective in reducing As bioaccessibility.

\section{Effect of Dietary Components on Bioaccessibility of Ca, Mg, K, Fe, and $\mathrm{P}$ in Food}

Matrices. Table 2 shows the changes in the soluble contents of these mineral elements in samples of white rice, brown rice, and seaweed as a result of applying gastrointestinal digestion in the presence of $\mathrm{Fe}(\mathrm{II}), \mathrm{Fe}(\mathrm{III}), \mathrm{TiO}_{2}$, and tannic acid, components that reduced As bioaccessibility in the three foods by more than $35 \%$.

In seaweed, only the presence of tannic acid reduced the soluble contents of $\mathrm{K}$, Fe, and P; the other components did not produce reductions greater than $8 \%$, and in some cases an increase in concentration was observed, possibly due to the chemical composition of the dietary components assayed. In the rice samples, the minerals most affected by the components were $\mathrm{Ca}$, Fe, and $\mathrm{P}$, with reductions in soluble contents that varied depending on the type of rice. In white rice, notable reductions of $\mathrm{Ca}$ and $\mathrm{P}$ were produced by $\mathrm{Fe}(\mathrm{III})$, and of Fe by tannic acid. In brown rice, the iron salts and titanium dioxide reduced the soluble fractions of $\mathrm{Ca}$ and $\mathrm{P}$ after gastrointestinal digestion, in proportions varying between 38 and $90 \%$. There were also notable reductions of Fe in the presence of titanium dioxide (reduction of $100 \%$ ), and tannic acid (reduction of $90 \%$ ). 


\section{DISCUSSION}

A contaminant that is present in food reaches the systemic circulation as a result of a series of processes that take place between its ingestion and its absorption. Earlier studies evaluated the bioavailability (quantity of contaminant that reaches the systemic circulation) in laboratory animals and showed that it depends largely on the chemical form of the metalloid. Inorganic As is easily absorbable irrespective of the concentration and the type of animal employed. The absolute bioavailability in experimental animals of a single dose of As(III) or As(V) administrated by gavage is greater than $75 \% .{ }^{16-19}$ The absorption reported for DMA(V) is more variable, with bioavailability ranging between $33 \%$ in swine ${ }^{19}$ and $80 \%$ in rodents. ${ }^{20}$ Most of the studies on absorption have been conducted with aqueous standards of As species, and, although it is true that drinking water is an important source of exposure, it must not be forgotten that this metalloid is also carried by foods.

There are few studies that evaluate the absorption of As from food or in the presence of food matrices. Juhasz et al. ${ }^{12,19}$ showed As bioavailability in swine fed by gavage of 33-89\% for rice, $98 \%$ for beans, $70 \%$ for radish, $52 \%$ for chard, and $50 \%$ for lettuce. They attributed the differences in bioavailability in rice samples to the different chemical species of As that they contained, with the ones in which DMA was the major species having the lowest bioavailability. The lower bioavailability of As observed in some vegetables in comparison with rice has been related to their non-digestible polysaccharide component. Gonzalez et al., ${ }^{21}$ using two complementary approaches, showed that $\mathrm{As}(\mathrm{V})$ absorption decreased in the presence of phosphate. This effect was subsequently verified in vitro using Caco-2 cells and increasing concentrations of phosphate, ${ }^{22}$ and it was attributed to the fact that the two elements share transport mechanisms in the intestinal epithelium. ${ }^{23}$ The studies just cited show that there are dietary components that can reduce the bioavailability of As, and that they could be used as strategies to reduce intestinal absorption of this metalloid. 
After ingestion of food, the quantity of contaminant that reaches the systemic circulation can be reduced by acting at various levels. Possibly one of the most suitable approaches is the use of compounds that bind the As solubilized during digestion, producing compounds with low solubility. This approach was used in the present work; the components to be assayed were selected on the basis of the information published about strategies for eliminating As from waste and drinking water, in which inorganic As is the main species. The compounds most employed for this purpose are iron, aluminum, manganese, and titanium salts. ${ }^{24-25}$ The results of this work showed that in the presence of iron, aluminum, and titanium there was a considerable reduction in the quantity of soluble As after gastrointestinal digestion. This decrease took place in aqueous standards and in food samples, although the effect of the food matrix was clearly observed. For example, in seaweed the reduction in bioaccessibility was less after treatment with iron salts and aluminum, indicating that some of the food components may interfere with the adsorption/coagulation of As. This result is similar to those found in environmental studies that showed that the presence of high concentrations of phosphates, sulfates, and silicates reduced the effectiveness of treatment with iron or aluminum oxides. ${ }^{26-27}$

In arsenic removal from water/wastewater it has been verified that adsorbents/coagulants in the form of salts act more effectively on $\mathrm{As}(\mathrm{V})$ than on $\mathrm{As}(\mathrm{III})$, and oxidation of $\mathrm{As}(\mathrm{III})$ to As(V) has even been recommended as a necessary step in elimination strategies. ${ }^{28}$ However, this effect was not observed in As(III) and As(V) standards after the gastrointestinal digestion process, given that iron and titanium reduced the solubility of the two inorganic species equally. Earlier studies conducted by our group showed that the conditions used in the gastrointestinal digestion method do not produce changes in the oxidation state of As(III) and $\mathrm{As}(\mathrm{V}) ;{ }^{29}$ however, it has not been evaluated whether the presence of iron salts and titanium dioxide can produce oxidation of As(III). The effect of the salts employed on the 
gastrointestinal solubility of DMA(V) was less; a similar result has been observed in water, in which the use of $\mathrm{Fe}$ and $\mathrm{Al}$ as adsorbents for the elimination of DMA(V) was less effective than for inorganic As. ${ }^{30-31}$ Lafferty and Loepper ${ }^{32}$ suggested that the differences observed in the percentages of adsorption could have been a consequence of a possible reduction in spatial compatibility with surface adsorption sites, owing to its two additional methyl groups.

The compounds assayed form part of the composition of food or are used as food additives, so using them as a dietary strategy at suitable concentrations should not present any problems. For example, iron is one of the main minerals in foods and is also used as a food supplement. Furthermore, in the European Union, titanium dioxide (E171) is listed in Annex I of Directive 94/36/EC as a permitted color in foodstuffs. ${ }^{33}$ Also, the United States Food and Drug Administration ${ }^{34}$ has authorized the use of titanium dioxide in food, in general, at a limit not to exceed $1 \%$ by weight of the food. Moreover, the Panel on Food Additives, Flavourings, Processing Aids and Materials in Contact with Food ${ }^{35}$ concluded that the use of rutile titanium dioxide in the platelet or amorphous form as food color would not pose any safety concerns. Aluminum is also authorized as an additive. European Parliament and Council Directive 95/2/EC on food additives other than colors and sweeteners (as amended) allows a number of aluminum-containing additives to be used in some foodstuffs; specifically, aluminum sulfates (E520-E523) are permitted to be used in egg white and candied, crystallized, and glacé fruit and vegetables. ${ }^{36}$ However, unlike titanium, aluminum can have some toxicological implications at certain concentrations. ${ }^{37}$ The Joint FAO/WHO Expert Committee on Food Additives $^{38}$ proposes a provisional tolerable intake of $0.15 \mathrm{mg} / \mathrm{kg}$ body weight per day, which amounts to an intake of $9 \mathrm{mg} / \mathrm{day}$ for an adult weighing $60 \mathrm{~kg}$. In our study, the main reductions in As bioaccessibility take place at concentrations between 5 and $50 \mathrm{mg}$; therefore, although aluminum sulfate was effective in eliminating As from the fraction available for 
intestinal absorption, the concentrations required are not suitable to ensure complete safety of the strategy.

In addition to the effect on bioaccessibility observed in the presence of the salts just mentioned, a considerable reduction was also produced by tannic acid in rice and seaweed samples. Tannic acid is rich in carboxyl groups and therefore tends to interact with cations in solution, such as $\mathrm{Cd}$ and $\mathrm{Pb}^{39}$ In fact, it has been seen that administering a $2 \%$ solution of tannic acid alternately with $\mathrm{Pb}$ or $\mathrm{Cd}$ to rats was an effective method for reducing the contents of these toxic trace elements. ${ }^{40}$ However, the complexation of tannic acid to As species, negatively charged, is difficult to explain. There is a possibility that after digestion part of the As may be bound to proteins, small peptides, or other macromolecules, and in this form it may interact with tannic acid. Protein and tannic acid interact to form soluble and insoluble complexes, and the latter are favored by a $\mathrm{pH}$ near the isoelectric point of the protein and an excess of tannic acid. ${ }^{41}$

Finally, it is noteworthy that some organic compounds that were ineffective in rice, such as sodium alginate, phytate combined with calcium, lignin, xylan, or malic acid, markedly reduced As bioaccessibility in seaweed. The difference among samples could be a consequence of the matrix composition or due to their arsenic profile. It should be noted that the major species in the rice was inorganic As because, as mentioned earlier, the samples were cooked with water to which As(V) had been added; however, in the seaweed a combination of inorganic As and arsenosugars was present, in proportions that varied depending on the sample. The differences observed between matrices indicate that it is necessary to characterize, as far as possible, the compound/As interaction for each food product in order to select the strategies that are most effective in reducing As bioaccessibility.

The benefit represented by the decrease in As bioaccessibility resulting from the strategies described is not the only aspect to be evaluated. These dietary components could affect the 
nutritional value of foodstuffs and entail a risk that should be evaluated in vitro before going ahead with implementation. The present study shows that some of the components assayed produced a significant decrease in the soluble contents of major minerals, especially in samples of rice. The decreases for $\mathrm{Ca}$ and Fe were notable, but their impact on the daily recommended quantity for each of them must be evaluated in the context of a complete diet.

Reducing oral exposure to As is one of the recommendations of food safety authorities. The use of iron and titanium, or the incorporation of tannic acid in the diet, either as supplements or else as food additives, may be strategies for achieving this aim, because in vitro they reduced the bioaccessibility of As after gastrointestinal digestion. These components, which are customarily ingested with the diet, cannot be considered as harmful at the concentrations used in our study. However, in some cases the addition of these compounds produced a reduction in the soluble contents not only of As but also of other essential minerals, especially in the case of $\mathrm{Ca}$ and $\mathrm{Fe}$ in rice samples. Moreover, the efficiency of the strategies should be evaluated in the context of complete diets because the dietary components provided by other foods consumed at the same time as rice or seaweed might affect the solubilization of arsenic.

The effectiveness of the strategies proposed must be confirmed in vivo, because the interaction observed during digestion in vitro may be affected by other components present in the lumen, especially by the action of intestinal microbiota. The strategies might also affect the process of absorption of arsenic and/or minerals. Moreover, it is necessary to evaluate whether the risk that they entail as a result of the reduction in the bioaccessibility of minerals affects the nutritional state in vivo. 


\section{REFERENCES}

1. WHO, World Health Organization. Arsenic in Drinking-water. Background document for development of WHO Guidelines for Drinking-water Quality. World Health Organization, Geneva, 2011.

2. Bundschuh, J.; Litter, M. I.; Parvez, F.; Román-Ross, G.; Nicolli, H. B.; Jean, J. S.; Liu, C. W.; López, D.; Armienta, M. A.; Guilherme, L. R.; Cuevas, A. G.; Cornejo, L.; Cumbal, L.; Toujaguez, R. One century of arsenic exposure in Latin America: A review of history and occurrence from 14 countries. Sci. Total Environ. 2012, 429, 2-35.

3. Vahter, M.; Lind, B. Concentrations of arsenic in urine of the general population in Sweden. Sci. Total Environ. 1986, 54, 1-12.

4. Concha, G.; Nermell, B.; Vahter, M. Spatial and temporal variations in arsenic exposure via drinking-water in northern Argentina. J. Health Popul. Nutr. 2006, 24, 317-326.

5. Chen, C. J.; Chen, C.W.; Wu, M. M.; Kuo, T. L. Cancer potential in liver, lung, bladder and kidney due to ingested inorganic arsenic in drinking water. Br. J. Cancer 1992, 66, 888892.

6. EFSA, European Food Safety Authority. Scientific opinion on arsenic in food. EFSA Panel on Contaminants in the Food Chain (CONTAM). EFSA J. 2009, 7(10), 1351, 1-199.

7. Brammer, H. Mitigation of arsenic contamination in irrigated paddy soils in South and South-East Asia. Environ. Int. 2009, 35, 856-863.

8. Zhao, F. J.; Ma, J. F.; Meharg, A. A.; McGrath, S. P. Arsenic uptake and metabolism in plants. New Phyt. 2009, 181, 777-794.

9. Bogdan, K.; Schenk, M. K. Arsenic in rice (Oryza sativa L.) related to dynamics of arsenic and silicic acid in paddy soils. Environ. Sci. Technol. 2008, 42, 7885-7890. 
10. Li, R. Y.; Stroud, J. L.; Ma, J. F.; McGrath, S. P.; Zhao, F. J. Mitigation of arsenic accumulation in rice with water management and silicon fertilization. Environ. Sci. Technol. 2009, 43, 3778-3783.

11. Dhankher, O. P.; Paulose, B.; Chhikara, S.; Kumar, K.; Mosa, K. A. Engineering plants for arsenic containment: what we know and where should we go? International Conference on Green Remediation (Environment, Energy, Economics), University of Massachusetts, Amherst, Massachusetts, USA, 2010, June, 15-17.

12. Juhasz, A. L.; Smith, E.; Weber, J.; Rees, M.; Rofe, A.; Kuchel, T.; Sansom, L.; Naidu, R. Application of an in vivo swine model for the determination of arsenic bioavailability in contaminated vegetables. Chemosphere, 2008, 71, 1963-1969.

13. Laparra, J. M.; Velez, D.; Montoro, R.; Barbera, R.; Farre. R. Estimation of arsenic bioaccessibility in edible seaweed by an in vitro digestion method. J. Agric. Food Chem. 2003, 51, 6080-6085.

14. Muñoz, O.; Díaz, O. P.; Leyton, I.; Núñez, N.; Devesa, V.; Súñer, M. A.; Vélez, D.; Montoro, R. Vegetables collected in the cultivated Andean area of northern Chile. Total and inorganic arsenic contents in raw vegetables. J. Agric. Food Chem. 2002, 50, 642-647.

15. Codex Alimentarius Commission. Proposed draft maximum levels for arsenic in rice. Committee CX/CF 12/6/8. JOINT FAO/WHO Food Standards Programme. Codex committee on contaminants in foods. Sixth session. Maastricht, The Netherlands, 2012, 26-30.

16. Vahter, M.; Norin, H. Metabolism of ${ }^{74}$ As-labeled trivalent and pentavalent inorganic arsenic in mice. Environ. Res. 1980, 21, 446-457.

17. Freeman, G. B.; Schoof, R. A.; Ruby, M. V.; Davis, A. O.; Dill, J. A.; Liao, S. C.; Lapin, C. A.; Bergstrom, P. D. Bioavailability of arsenic in soil and house dust impacted by smelter activities following oral administration in cynomolgus monkeys. Fund. Appl. Toxicol. 1995, 28, 215-222. 
18. Roberts, S. M.; Weimar, W. R.; Vinson, J. R.; Munson, J. W.; Bergeron, R. J. Measurement of arsenic bioavailability in soil using a primate model. Toxicol. Sci. 2002, 67, 303-310.

19. Juhasz, A. L.; Smith, E.; Weber, J.; Rees, M.; Rofe, A.; Kuchel, T.; Sansom, L.; Naidu, R. In vivo assessment of arsenic bioavailability in rice and its significance for human health risk assessment. Environ. Health Perspect. 2006, 114, 1826-1831.

20. Vahter, M.; Marafante, E.; Dencker, L. Tissue distribution and retention of ${ }^{74}$ Asdimethylarsinic acid in mice and rats. Arch. Environ. Contam. Toxicol. 1984, 13, 259-264.

21. Gonzalez, M. J.; Aguilar, M. V.; Martinez, M. C. Gastrointestinal absorption of inorganic arsenic (V): The effect of concentration and interactions with phosphate and dichromate. Vet. Human Toxicol. 1995, 37, 131-136.

22. Calatayud, M.; Gimeno, J.; Vélez, D.; Devesa, V.; Montoro, R. Characterization of the intestinal absorption of arsenate, monomethylarsonic acid, and dimethylarsinic acid using the Caco-2 cell line. Chem. Res. Toxicol. 2010, 23, 547-556.

23. Calatayud, M.; Barrios, J. A.; Vélez, D.; Devesa, V. In vitro study of transporters involved in intestinal absorption of inorganic arsenic. Chem. Res. Toxicol. 2012, 25, 446-453. 24. Bissen, M.; Frimmel, F. H. Arsenic - a Review. Part II: Oxidation of Arsenic and its Removal in Water Treatment. Acta Hydrochim. Hydrobiol. 2003, 31, 97-107.

25. Mohan, D.; Pittman, C. U. Arsenic removal from water/wastewater using adsorbents. A critical review. J. Haz. Mat. 2007, 142, 1-53.

26. Jeong, Y.; Fan, M.; Van Leeuwen, J.; Belczyk, J. F. Effect of competing solutes on arsenic (V) adsorption using iron and aluminum oxides. J. Environ. Sci. (China), 2007, 19, 910-919. 
27. Tuutijärvi, T.; Repo, E.; Vahala, R.; Sillanpää, M.; Chen, G. Effect of competing anions on arsenate adsorption onto maghemite nanoparticles. Chin. J. Chem. Eng. 2012, 20, 505514.

28. Sorlini, S.; Gialdini, F. Conventional oxidation treatments for the removal of arsenic with chlorine dioxide, hypochlorite, potassium permanganate and monochloramine. Water Res. 2010, 44, 5653-5659.

29. Calatayud, M.; Bralatei, E.; Feldmann, J.; Devesa, V.; Vélez, D. Transformation of arsenic species during in vitro gastrointestinal digestion of vegetables. J. Agric. Food Chem. 2013, 61, 12164-12170.

30. Cheng, Z.; Van Geen, A.; Louis, R.; Nikolaidis, N.; Bailey, R. Removal of methylated arsenic in groundwater with iron filings. Environ. Sci. Technol. 2005, 39, 7662-7666.

31. Shimizu, M.; Ginder-Vogel, M.; Parikh, S. J.; Sparks, D. L. Molecular scale assessment of methylarsenic sorption on aluminum oxide. Environ. Sci. Technol. 2010, 44, 612-617.

32. Lafferty, B. J.; Loeppert, R. H. Methyl arsenic adsorption and desorption behavior on iron oxides. Environ. Sci. Technol. 2005, 39, 2120-2127.

33. EU, European Union. European Parliament and Council Directive 94/36/EC of 30 June 1994 on colours for use in foodstuffs. Official Journal of the European Communities. 1994, No L 237/13.

34. FDA, Food and Drug Administration. Titanium dioxide. United States Code of Federal Regulations. 2005. Title 21, Volume 1. Revised as of April 1, 2014. Section 73.575.

35. EFSA, European Food Safety Authority. Opinion of the Scientific Panel on Food Additives, Flavourings, Processing Aids and Materials in Contact with Food on a request from the Commission related to the safety in use of rutile titanium dioxide as an alternative to the presently permitted anatase form. EFSA J. 2004, 163, 1-12. 
36. EU, European Union. European Parliament and Council Directive No 95/2/EC of 20 February 1995 on food additives other than colours and sweeteners. 1995.

37. EFSA, European Food Safety Authority. Safety of aluminium from dietary intake. Scientific Opinion of the Panel on Food Additives, Flavourings, Processing Aids and Food Contact Materials (AFC). EFSA J. 2008, 754, 1-34.

38. JECFA, Joint FAO/WHO Expert Committee on Food Additives. Safety evaluation of certain additives and contaminants. Sixty-seventh meeting of JECFA. International Programme on Chemical Safety. 2007. WHO Food additive series 58, Geneva.

39. Pekdemir, T.; Tokunaga, S.; Ishigami, Y.; Hong, K. J. Removal of cadmium or lead from polluted water by biological amphiphiles. J. Surfact. Deterg. 2000, 3, 43-46.

40. Winiarska-Mieczan, A.; Krusiński, R.; Kwiecień, M. Tannic acid influence on lead and cadmium accumulation in the hearts and lungs of rats. Adv. Clin. Exp. Med. 2013, 22, 615620.

41. Van Buren, J. P.; Robinson, W. B. Formation of complexes between protein and tannic acid. J. Agric. Food Chem. 1969, 17, 772-777.

FUNDING SOURCES. This work was supported by the Spanish Ministry of Economy and Competitiveness (AGL2012-33461), for which the authors are deeply indebted. 
Table 1. Dietary Components used in the Study (Concentrations Expressed in g in $100 \mathrm{~mL}$ of Digested Solution).

\begin{tabular}{|c|c|c|c|}
\hline Dietary components & $\begin{array}{l}\text { Concentration } \\
\text { (As solutions) }^{\mathrm{a}}\end{array}$ & $\begin{array}{l}\text { Concentration } \\
{\text { (food matrix })^{\mathrm{a}}}^{\text {(fod }}\end{array}$ & Brand \\
\hline Aluminum sulfate & $0.005 ; 0.05$ & $0.005 ; 0.05$ & Fluka \\
\hline Calcium carbonate & $0.25 ; 0.50$ & n.a & Sigma-Aldrich \\
\hline $\begin{array}{l}\text { Calcium chloride anhydrous/Phytic acid } \\
\text { dipotassium salt }\end{array}$ & $\begin{array}{c}0.55 / 0.11 \\
1.4 / 0.28\end{array}$ & $\begin{array}{c}0.55 / 0.11 \\
1.4 / 0.28\end{array}$ & Panreac/ Sigma-Aldrich \\
\hline Carboxymethylcellulose (CMC) & $1.6 ; 3.2$ & n.a & AKUCELL \\
\hline$\lambda$ Carrageenan & $0.215 ; 0.45$ & n.a & Cargill \\
\hline Catechin hydrate & $0.05 ; 0.2$ & n.a & Fluka \\
\hline Chitosan medium molecular weight & 0.5 & n.a & Aldrich \\
\hline Citric acid 1-hydrate & 0.06 & n.a & Panreac \\
\hline Copper sulfate & 0.002 & n.a & Sigma-Aldrich \\
\hline Gelatin from porcine skin & $0.5 ; 1$ & n.a & Sigma \\
\hline Guar gum & $0.5 ; 1$ & n.a & Fluka \\
\hline Gum arabic from acacia tree & $0.5 ; 1$ & n.a & Fluka \\
\hline Hydroxypropylmethylcellulose (HPMC) & $0.2 ; 0.4$ & $0.2 ; 0.4$ & Dow Chemical company \\
\hline Hydroxypropyl cellulose (HPC) & $0.2 ; 0.4$ & $0.2 ; 0.4$ & Aldrich \\
\hline Iron(II) sulfate heptahydrate & $0.015 ; 0.100$ & $0.030 ; 0.100$ & Sigma-Aldrich \\
\hline Iron(III) sulfate hydrate & $0.015 ; 0.100$ & $0.030 ; 0.100$ & Scharlau \\
\hline L-Cysteine (L-Cys) & $0.01 ; 0.50$ & n.a & Merck \\
\hline Lignin, alkali & $0.4 ; 1.4$ & $0.4 ; 1.4$ & Aldrich \\
\hline$( \pm)$ - $\alpha$-Lipoic acid & $0.024 ; 0.08$ & n.a & Sigma \\
\hline$( \pm)$ - $\alpha$-Lipoic acid reduced & $0.012 ; 0.04$ & n.a & Sigma \\
\hline Magnesium chloride & 0.5 & n.a & Sigma-Aldrich \\
\hline Malic acid & 0.8 & $0.8 ; 1.6$ & Sigma-Aldrich \\
\hline Manganese oxide & $0.005 ; 0.011$ & $0.005 ; 0.011$ & Sigma-Aldrich \\
\hline Methylcellulose (MC) & 0.2 & n.a & Dow Chemical company \\
\hline N-acetylcysteine (NAC) & $0.6 ; 1.2$ & $0.6 ; 1.2$ & Sigma \\
\hline Oxalic acid dihydrate & $0.075 ; 0.150$ & $0.075 ; 0.150$ & Merck \\
\hline Pectin from apple & 1.0 & $1 ; 2$ & Sigma \\
\hline Phytic acid dipotassium salt & $0.1 ; 0.50$ & n.a & Sigma-Aldrich \\
\hline Saponin & $1.5 ; 2.0$ & $1.5 ; 2.0$ & Santa Cruz Biotechnology \\
\hline Seleno-D-L-methionine (SeMet) & $0.1 \times 10^{-3}$ & $(0.1,0.3) \times 10^{-3}$ & Sigma \\
\hline Sodium alginate & 0.2 & $0.2 ; 0.4$ & EPSA \\
\hline Tannic acid & $0.5 ; 3.32$ & $0.5 ; 1$ & Merck \\
\hline Titanium dioxide & $0.005 ; 0.02$ & $0.005 ; 0.02$ & Sigma-Aldrich \\
\hline Xanthan gum from $X$. campestris & $0.5 ; 1$ & n.a & Sigma \\
\hline Xylan from oat spelts & $0.4 ; 1.4$ & $0.4 ; 1.4$ & Sigma \\
\hline
\end{tabular}

${ }^{a}$ The numbers indicate the low and high concentrations employed in the assays; n.a: not assayed. 
Table 2. Percentage of Modification of the contents of Ca, Mg, K, Fe, and P in the soluble fraction of Cooked Food Samples after Applying a Gastrointestinal Digestion with and without the presence of Dietary Components (Concentrations Expressed in $\mathrm{g}$ in $100 \mathrm{~mL}$ of Digested Solution). Values expressed as mean $(n=2)$. Asterisks indicate statistically significant differences with respect to the food samples digested without components $(\mathrm{p}<$ 0.05). Negative values indicate decreases in solubility with respect to the digestion without components.

\begin{tabular}{|c|c|c|c|c|c|c|}
\hline & $\begin{array}{l}\text { Dietary component } \\
\text { (g/100 mL) }\end{array}$ & Ca & Mg & $\mathbf{K}$ & $\mathbf{F e}$ & $\mathbf{P}$ \\
\hline \multirow{4}{*}{ 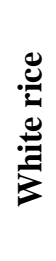 } & Fe(II) (0.03) & 0.5 & $-17^{*}$ & -1 & $2400 *$ & $68 *$ \\
\hline & $\mathrm{Fe}(\mathrm{III})(0.03)$ & $-81^{*}$ & 11 & -5 & $721^{*}$ & $-80 *$ \\
\hline & $\mathrm{TiO}_{2}(0.02)$ & $22^{*}$ & -12 & -9 & $100^{*}$ & -6 \\
\hline & Tannic acid (0.5) & $316^{*}$ & $891^{*}$ & -3 & $-95^{*}$ & $89 *$ \\
\hline \multirow{4}{*}{ 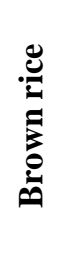 } & Fe(II) (0.03) & $-63^{*}$ & $16^{*}$ & $-25^{*}$ & $386^{*}$ & $-83 *$ \\
\hline & $\mathrm{Fe}(\mathrm{III})(0.03)$ & $-90^{*}$ & -7 & $-37 *$ & $2064 *$ & $-54^{*}$ \\
\hline & $\mathrm{TiO}_{2}(0.02)$ & $-67 *$ & -5 & $-19 *$ & $-100^{*}$ & $-38^{*}$ \\
\hline & Tannic acid (0.5) & $51 *$ & $2899 *$ & $576^{*}$ & $-94 *$ & $979 *$ \\
\hline \multirow{4}{*}{ Dٌ } & $\mathrm{Fe}(\mathrm{II})(0.03)$ & $22^{*}$ & 4 & 11 & $21846^{*}$ & -8 \\
\hline & $\mathrm{Fe}(\mathrm{III})(0.03)$ & 4 & -2 & 0.2 & $24744^{*}$ & 11 \\
\hline & $\mathrm{TiO}_{2}(0.02)$ & 8 & $18^{*}$ & 10 & -4 & -7 \\
\hline & Tannic acid (0.5) & 12 & $671^{*}$ & $-29 *$ & $-100 *$ & $-92 *$ \\
\hline
\end{tabular}


Figure 1. Percentage of reduction of arsenic solubility after applying a gastrointestinal digestion in the presence of dietary components to a standard solution of As(III) $(1 \mathrm{mg} / \mathrm{L})$. Values expressed as mean \pm SD ( $n=3)$. Asterisks indicate statistically significant differences with respect to the standard solution digested without components $(\mathrm{p}<0.001)$. For each component the symbol $†$ indicates statistically significant differences between the low and high concentrations $(\mathrm{p}<0.001)$.

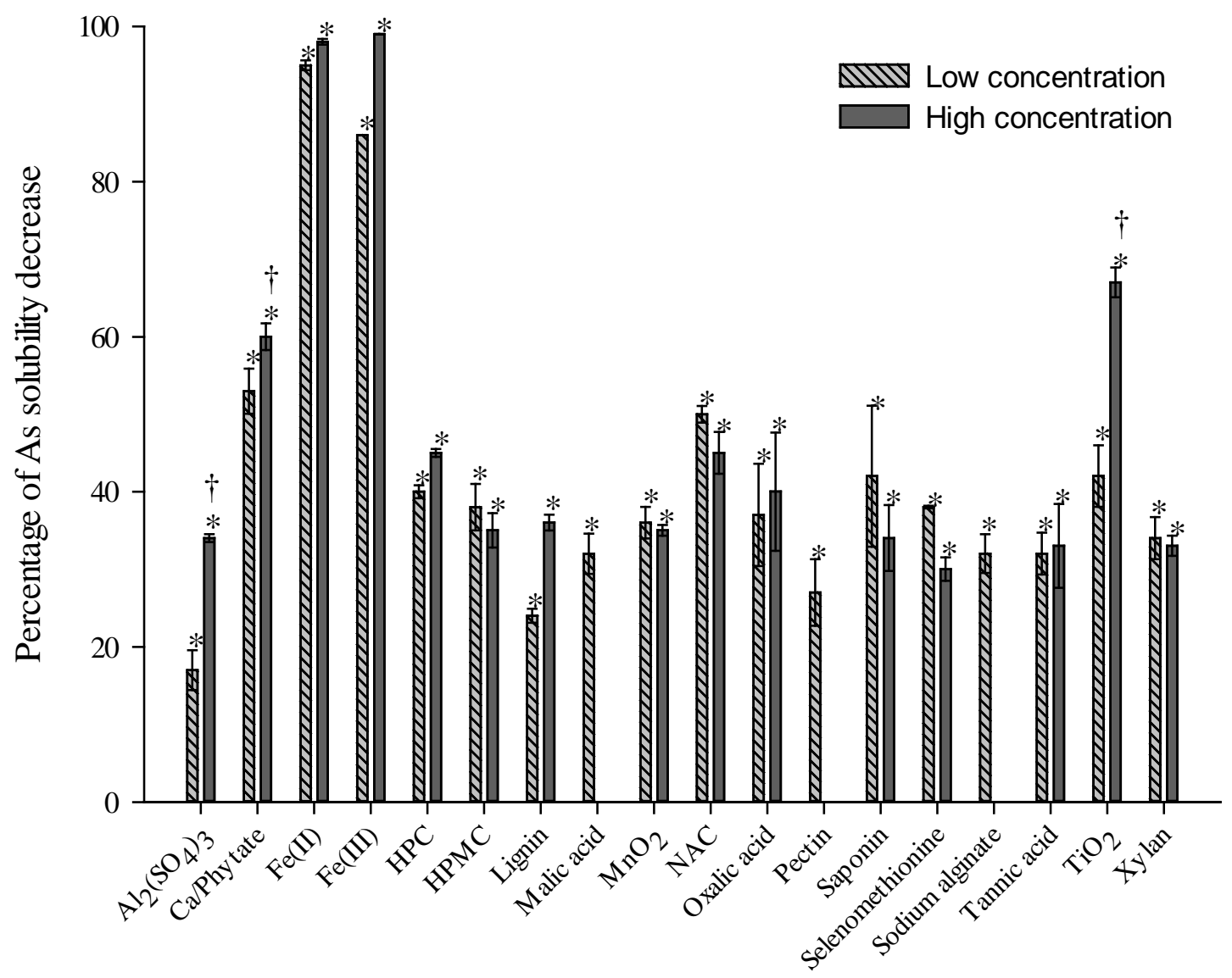


Figure 2. Percentage of reduction of arsenic solubility after applying a gastrointestinal digestion in the presence of dietary components to a standard solution of As(V) $(1 \mathrm{mg} / \mathrm{L})$. Values expressed as mean \pm SD ( $n=3)$. Asterisks indicate statistically significant differences with respect to the standard solution digested without components $(\mathrm{p}<0.001)$. For each component the symbol $†$ indicates statistically significant differences between the low and high concentrations $(\mathrm{p}<0.001)$.

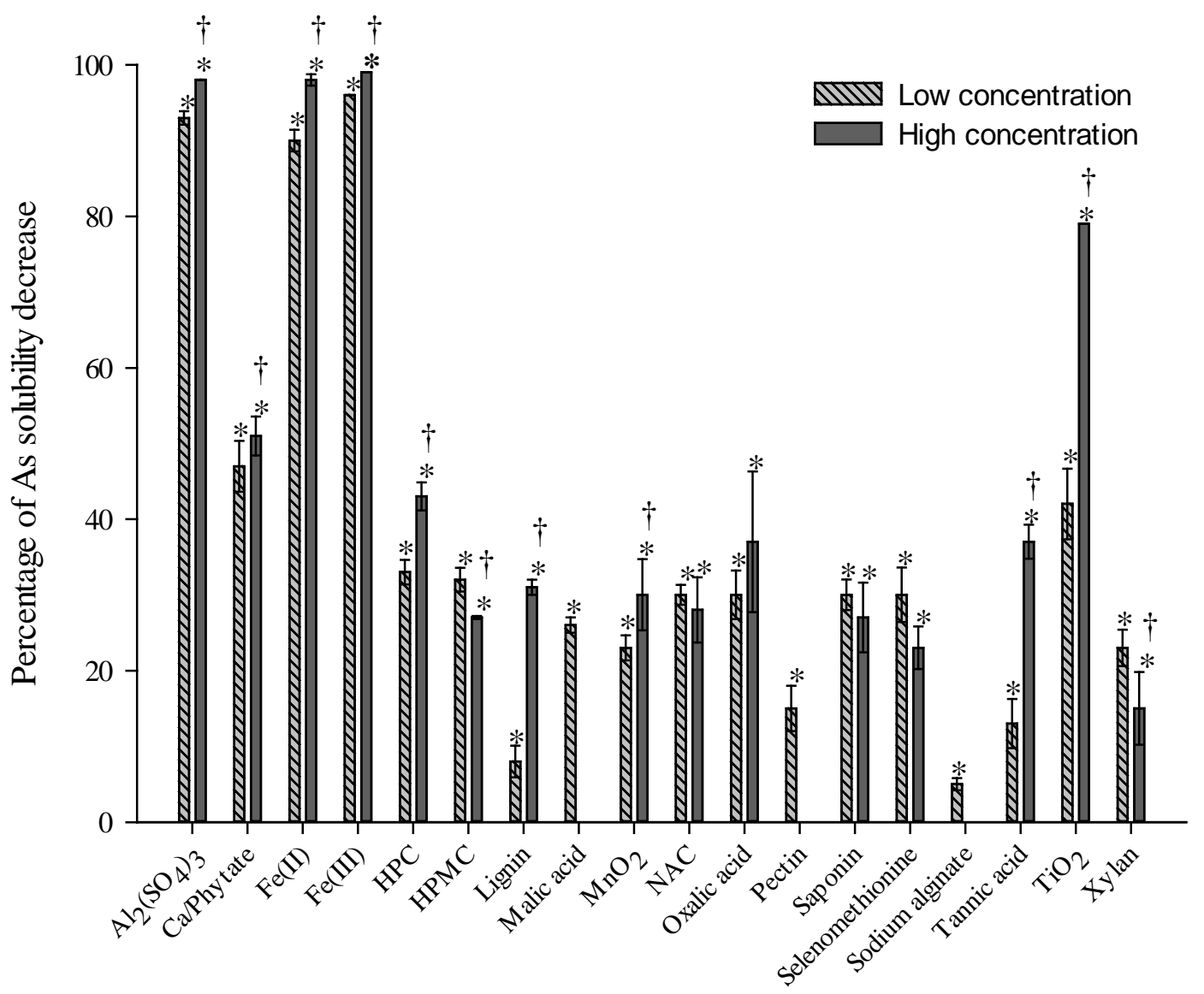


Figure 3. Percentage of reduction of arsenic solubility after applying a gastrointestinal digestion in the presence of dietary components to a standard solution of DMA(V) $(1 \mathrm{mg} / \mathrm{L})$. Values expressed as mean \pm SD ( $n=3)$. Asterisks indicate statistically significant differences with respect to the standard solution digested without components $(\mathrm{p}<0.001)$. For each component the symbol $\uparrow$ indicates statistically significant differences between the low and high concentrations $(\mathrm{p}<0.001)$.

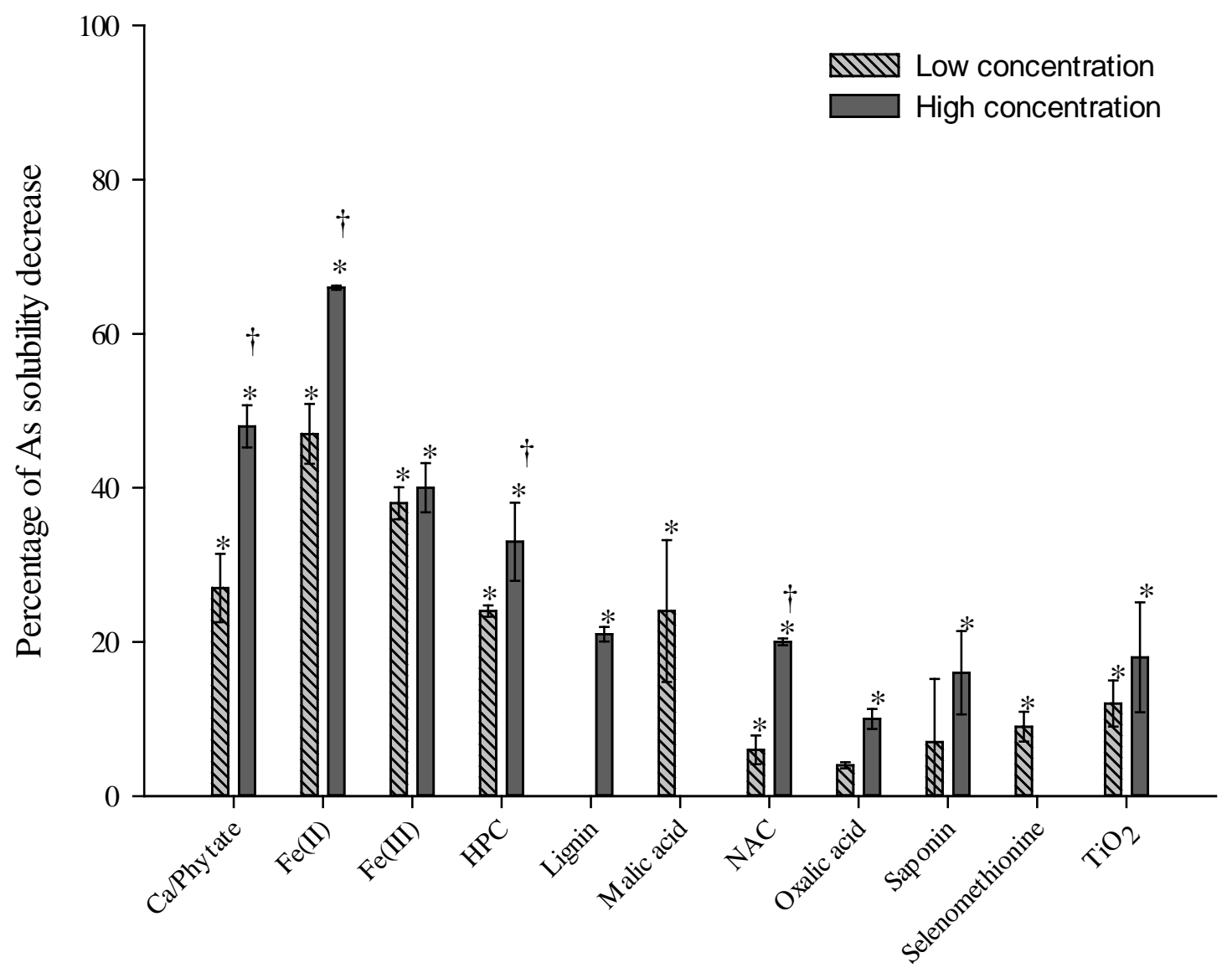


Figure 4. Percentage of reduction of As bioaccessibility in cooked white rice after applying a gastrointestinal digestion in the presence of dietary components. Values expressed as mean \pm SD $(n=3)$. Asterisks indicate statistically significant differences with respect to rice samples digested without components $(\mathrm{p}<0.001)$. For each component the symbol $\dagger$ indicates statistically significant differences between the low and high concentrations ( $\mathrm{p}<0.001)$.

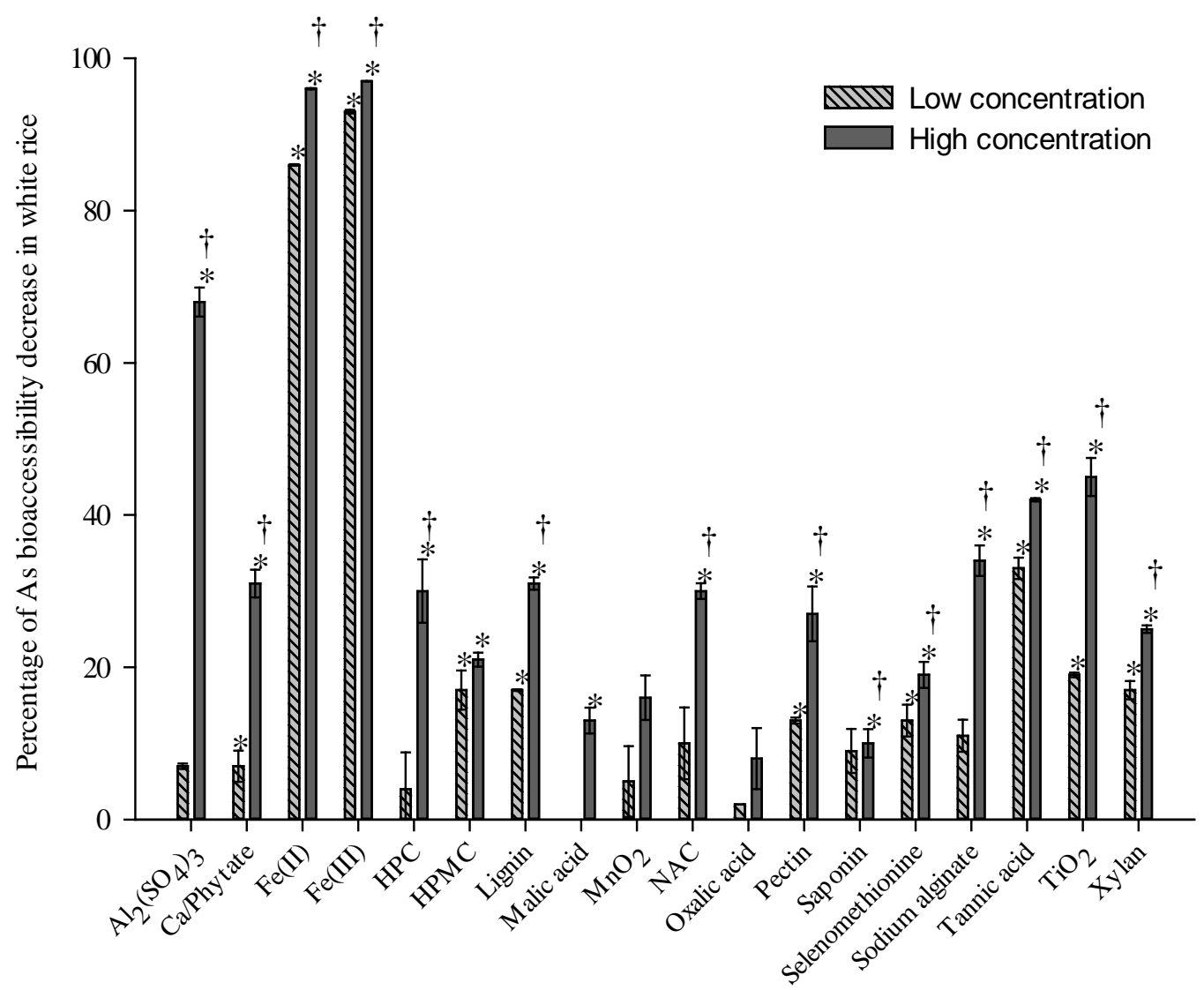


Figure 5. Percentage of reduction of As bioaccessibility in cooked brown rice after applying a gastrointestinal digestion in the presence of dietary components. Values expressed as mean \pm SD $(n=3)$. Asterisks indicate statistically significant differences with respect to rice samples digested without components $(p<0.001)$. For each component the symbol $\dagger$ indicates statistically significant differences between the low and high concentrations ( $\mathrm{p}<0.001)$.

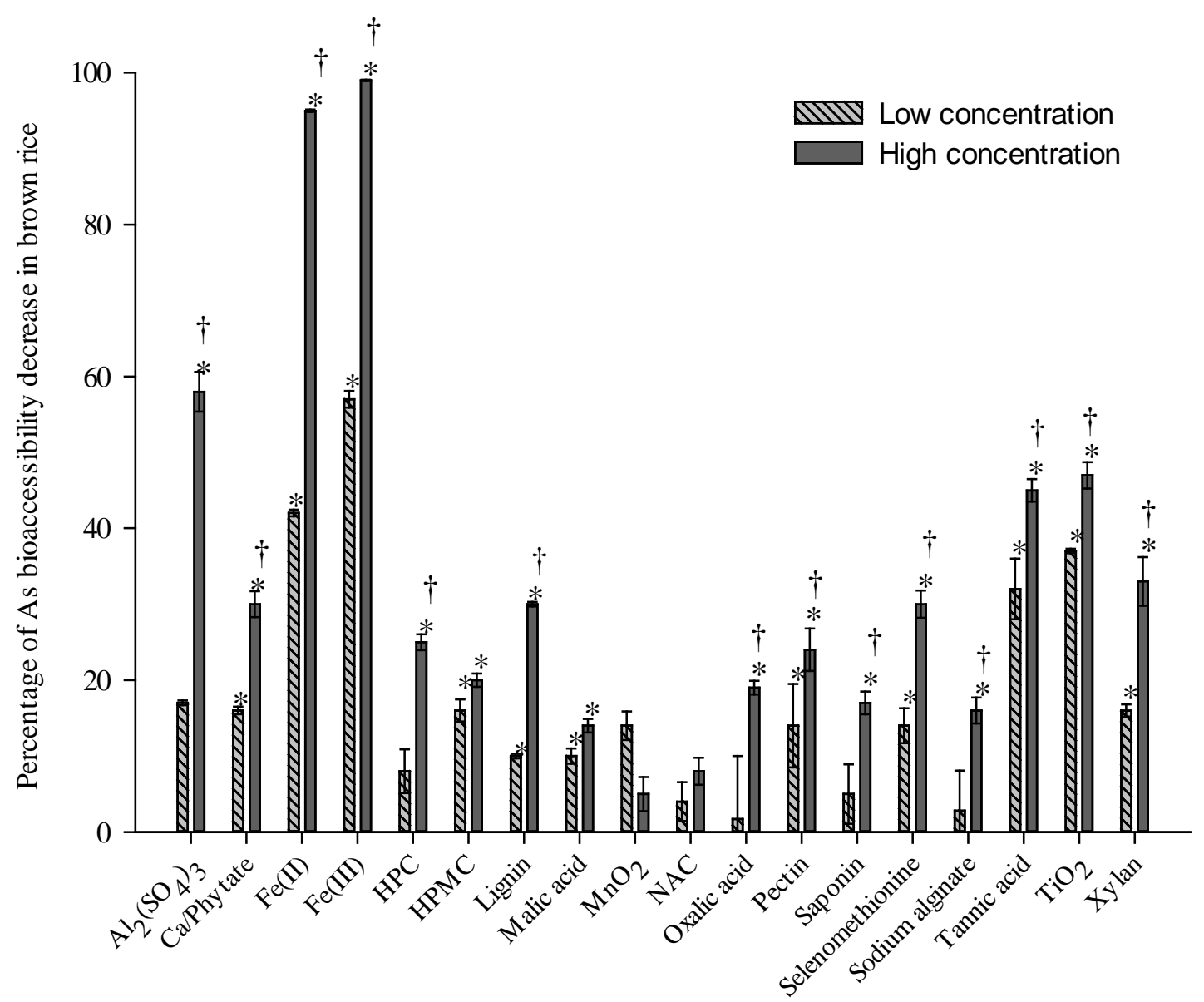


Figure 6. Percentage of reduction of As bioaccessibility in cooked seaweed after applying a gastrointestinal digestion in the presence of dietary components. Values expressed as mean \pm $\mathrm{SD}(\mathrm{n}=3)$. Asterisks indicate statistically significant differences with respect to seaweed samples digested without components $(\mathrm{p}<0.001)$. For each component the symbol $\dagger$ indicates statistically significant differences between the low and high concentrations $(\mathrm{p}<$ $0.001)$.

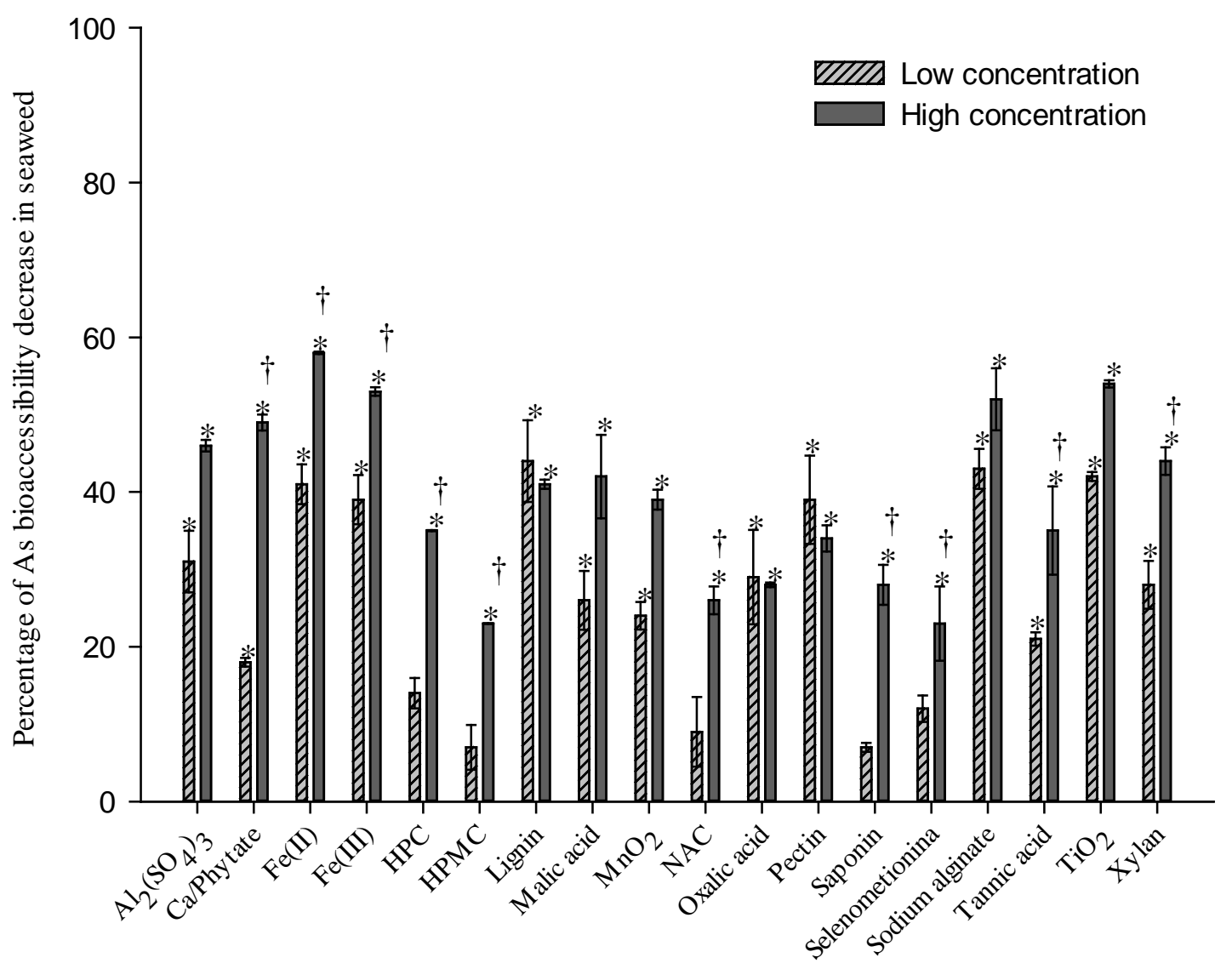




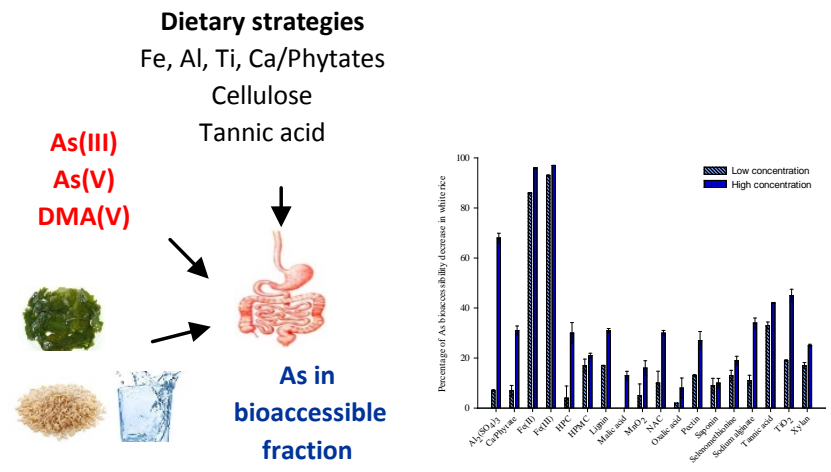

